\title{
What is the role of a Grandmother in a Malawian society and how can we as health care workers support her?
}

\section{S Jonasi}

5th Medical Student, College of Medicine

Grandparents are family members and form an important element of the extended family. In traditional cultures, grandparents often have a direct and clear role in relation to the care and nurture of children. This has tended to be lost with the development of the nuclear family. In cases where the parents are not willing or unable to provide adequate care for their children, grandparents may take on the role of primary caregivers. In traditional East Asian cultures influenced by Confucianism, filial piety is one of the highest moral values. Grandparents usually exercise their authority on family matters, and their descendants should obey their seniors. This kind of structure gradually eases with the increasing influence of western culture and the increasing number of nuclear families.

\section{Grandmothers as Primary Care Givers}

Grandmothers have a prominent and influential role within the family and are commonly in charge of child rearing when the mother is employed, sick or more commonly in our setting, orphaned due to the HIV/AIDS pandemic. They are often forced to resume the role of primary caregivers and it usually creates a financial constraint on them especially when the size of the family left behind is huge. It is even worse when the grandmother is a widow. Many children that are malnourished requiring admission onto the Nutrition Rehabilitation Unit are orphans being cared for by grandparents. In April 2007, a grandmother was found selling Chiponde feeds on the QECH wards, after obtaining them for a grandchild from the Moyo house. This is a pathetic situation, and displays the level of desperation that the new responsibility can cause. It is possible that there were more children who needed food at home and she needed to raise funds in order to feed them as well.

Older people caring for their dying children and orphaned grandchildren, especially those who are HIV-positive themselves, suffer from shame, fear and anxiety. Social isolation reduces their access to health services such as home visits and prevents them from using protective measures such as wearing gloves when caring for their sick grandchildren or relatives. Researchers found that in HIVaffected households run by older people, they are forced to abandon income-generation activities in order to take care of their grandchildren, making it difficult to pay for food, water, health care and education costs, which are four to five times higher than the household income. School attendance of orphaned children is affected and they do not usually continue to secondary education due to lack of financial resources, the elderly neither have time nor any help to cope with grief, loss and stress as they have to focus on running the household. ${ }^{1}$

As health care workers, we have to appreciate these challenges and provide advice and support on how to care for the children and provide good health. Home based care groups would be very helpful at the primary level, to assist

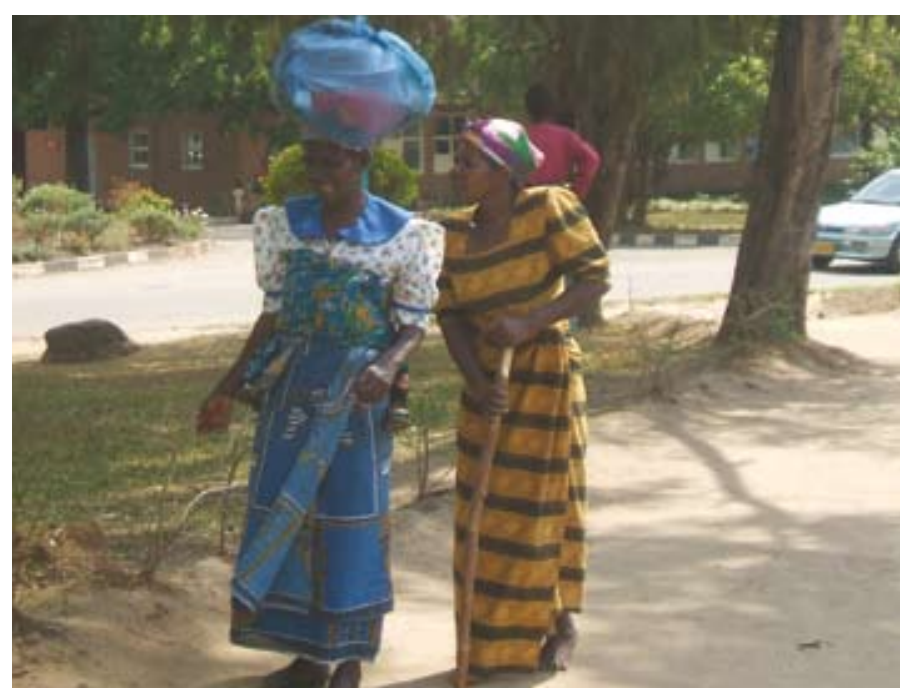

these families and address health needs at the community level. Importantly, to assist them in providing methods of generating funds such as farming cooperatives.

\section{Grandmothers as Partners to the Health Care System}

In societies in Africa, Asia, Latin America and the Pacific, older women, or grandmothers, traditionally have considerable influence on maternal and child health matters at the household level. However, most maternal and child health $(\mathrm{MCH})$ programmes focus exclusively on women of reproductive age. In a $\mathrm{MCH}$ project in Senegal, a community study showed that grandmothers and other older women continue to play a leading role in all household $\mathrm{MCH}$ decisions and activities. Based on these findings, an innovative, participatory nutrition education strategy was developed, which focused on grandmothers. A followup evaluation revealed positive changes in grandmothers' knowledge and advice to younger women, and in the younger women's nutritional practices. The strategy has contributed to grandmothers' sense of empowerment: It has acknowledged the important role they play in $\mathrm{MCH}$, improved their knowledge and skills, and strengthened their networks of friendship and solidarity with other grandmothers. ${ }^{2}$

Societies around the world acknowledge that grandmothers play an influential role in the socialization, acculturation, and care of children as they grow and develop and in the education and supervision of their daughters and daughtersin-law. A study concluded that while certain harmful practices are promoted by grandmothers in various cultures, given the wide-ranging role they play and their influence and intrinsic commitment to promoting the well being of women and children, they should be viewed as key actors in development programs. $^{3}$

The rationale for involving grandmothers in community programs is also supported by the policies of UNICEF, the World Bank and WHO related to the health and well 
being of women and children. Policy guidelines from these international organizations state that programs should build on local cultural realities, strengthen existing community resources and develop social capital for sustainable development. These policy principles provide additional support for the inclusion of knowledgeable, senior women as resource persons in community programs.

Grandmothers are a source of information, wisdom and comfort for many members of the community. People generally find comfort and confidence in seeking advise from their grandparent because the grandparents advice is taken with great respect, because it is associated with wisdom. In an attempt to capitalize on the respect accorded to grandmothers, the Alangizi Association has come up with a programme to update the skills of grandmothers who must treat and take care of their granddaughters and their newborns. Experience has shown that grandmothers are open to new ideas when engaged with participatory learning methods based on respect and dialogue. Grandmothers relate freely with their granddaughters and their husbands, giving them plenty of leverage when it comes to negotiating issues to do with reproductive health. The revival of the grandmother's role is based on an "assets" approach in which the focus is on strengthening the grandmother's knowledge as a community resource. The emphasis is on building grandmother networks, in recognition of the fact that they are already involved in giving advice on nutrition for new mothers and their babies and on community leadership. ${ }^{5}$

Grandmother-inclusive interventions have been associated with improvements in maternal and child well being in a number of settings. For example, in both Senegal and Mali, grandmother involvement contributed to better diet and nutritional status of pregnant women and young children ${ }^{4}$ In Laos, grandmother participation led to improved household care for diarrhoea, reducing risk of childhood death. ${ }^{4}$

In the final evaluation of the project it was found that there were positive improvements in grandmothers' knowledge and advice to other family members related to all eleven topics dealt with in the non-formal education strategy. For example, one of the key things taught to grandmothers was that when children have diarrhoea they need to be given lots of fluids. In the baseline study, only $30 \%$ of the grandmothers said that they advise giving "lots of fluids" to a child with diarrhoea whereas in the endline study $74 \%$ of grandmothers were giving this beneficial advice. Similarly, the proportion of grandmothers who advised mothers with young children to continue breast-feeding during diarrhoea increased greatly from $73 \%$ at the beginning of the project to $90 \%$ at end of the project. The evaluation results showed that grandmothers' own practices and advice to other family members had greatly improved. Given their influence in the family it can be concluded that these improvements contributed to improving home care of sick children and also to decreasing deaths among young children from common diseases, especially diarrhoea.

These results clearly show first, that the grandmothers were able to learn new things, second, that they improved the advice they give to younger women and third, that younger women were only able to put desired practices, like decreasing their workload, if their mothers-in-law agree. These significant results clearly support the need to include, rather than exclude grandmothers from such programs.

\section{Grandmothers as role models}

Grandmothers are a source of inspiration for many in the family. They are therefore in a position to set standards and goals for grandchildren, particularly if they themselves have been high achievers in their life. Unfortunately, most of our grandmothers in Malawi are illiterate, or are not conversant with the structures of the modern world, which they can avoid, but not their grandchildren, so this limits their effectiveness as role models, e.g. they are limited in the extent to which they can emphasize the need for education when they themselves are not literate. Their lack of awareness on modern contraceptive methods, maternal and child health services, modern health practices such as hygiene, results in conflict between what the she teaches her grandchildren, and the modern society in which the grandchildren are living in.

\section{Grandmother's Role in maintaining Culture}

They have a role in maintenance and nurturing grandchildren to grow up valuing traditional morals and beliefs, for example, they raise the girls to believe and accept the traditional female role, which is unfortunately one of dependence on the man as a breadwinner while her responsibility is to care for the family, which contradicts with the new feminist beliefs which emphasize on independence. Her importance in this scenario is that she creates a balance between the African culture and the western culture, so that the girl grows up having grasped the concepts of the modern woman and still appreciating the woman's role in the traditional society. So culture gets maintained to an extent.

\section{Conclusion}

Grandmothers have a role as primary care givers, can be successfully utilized and incorporated into formal health care systems. The health care system needs grandmothers, and measures such as home based care groups, farming cooperatives and education is essential in order to support and increase their accessibility to health care, financial and emotional constraints, and improve their effectiveness as partners.

\section{References}

1. Sangale L, Mgata M, \& Clark F. The cost of love: older people in the fight against AIDS in Tanzania', HelpAge International Tanzania, by Loserian Sangale and Mussa Mgata, November 2004

2. Aubel J,Toure I, Diagne M, Lazin K, Sene EHA, Faye Y, \& Tandia $\mathrm{M}$. 'Strengthening grandmother networks to improve community nutrition: experience from Senegal' by J. Aubel et al in Gender, Development and Health, Oxfam Focus on Gender Series, C. Sweetman (ed), 2001. http://www.grandmotherproject.org/

3. Aubel, J. \& D. Sihalathavong (2001), Participatory communication to strengthen the role of grandmothers in child health: an alternative paradigm for health education and health communication; Journal of International Communication, 7,2, 76-97.

4. Aubel, J., D. Sihalathavong \& D. Kopkeo. (1997) Participatory Health Education Project with Grandmothers in Laos. Vientiane.

5. Aubel, J. (2004). Generic Steps in the Grandmother-Inclusive Methodology. The Grandmother Project, Chevy Chase, Maryland. 